\title{
PROPERTIES OF STRAINS OF ESCHERICHIA COLI ISOLATED FROM A VARIETY OF SOURCES
}

\author{
E. Mary CoOKE* and Susan P. EwINS $\dagger$ \\ Department of Bacteriology, St Bartholomew's Hospital, London
}

THE species Escherichia coli is a large and heterogeneous group of organisms divided into types on the basis of their antigenic structure. There is some evidence that certain properties are found more commonly in strains isolated from disease processes than in those from normal faeces. These properties include haemolysin production, which has a high incidence in strains causing urinary-tract infections (Dudgeon, Wordley and Bawtree, 1921; Vahlne, 1945); necrotoxin production, which is associated with haemolysin production and is found in certain serotypes (Sjöstedt, 1946); cytotoxicity in tissue culture, closely associated with the production of soluble haemolysin (Chaturvedi et al., 1969); production of large amounts of $K$ antigen by strains infecting the kidney (Glyn, Brumfitt and Howard, 1971); and production of mucinase (Ross, 1959) and of enterotoxin (Taylor, Maltby and Payne, 1958) by strains causing infantile gastroenteritis.

Because of the evidence that carriage of $E$. coli round the external urethral meatus may be important in the pathogenesis of infection of the urinary tract (O'Grady et al., 1970), we have compared the properties of strains from this area which subsequently gave rise to infections of the urinary tract with strains which although colonising the urethral meatus did not give rise to infection. The association within strains of a number of different properties has also been studied.

\section{MATERIALS AND METHODS}

Fifty strains of $E$. coli from urinary-tract infections, 397 strains from normal faeces and 30 strains obtained by swabbing the external urethral meatus (introital strains) were examined. Of the 30 introital strains, 15 subsequently gave rise to infections of the urinary tract in the patients from whom they were isolated. The patients from whom the remaining 15 strains were obtained either did not develop infections during the three months following the isolation of the strain or developed an infection due to a different strain. All these organisms were examined for the production of haemolysin and necrotoxin and serotypes were determined.

To study the association in individual organisms of a number of different properties, 186 further strains of $E$. coli were examined. Fifty were from the faeces of ulcerative-colitis patients in remission, 50 from the faeces of ulcerative-colitis patients in relapse, 36 from the faeces of normal people and 50 from urinary-tract infections. These strains were not consecutive isolates but were chosen to include as far as possible equal numbers of haemolytic and

Received 26 Jan 1973; revised version accepted 20 June 1974.

* Present address: Department of Microbiology, School of Medicine, University of Leeds.

$\dagger$ Present address: 53 Tate Avenue, Wantirna South, Victoria 3152, Australia.

J. MED. MICROBIOL. - VOL. 8 (1975) 
non-haemolytic organisms and to include a wide range of serotypes. These strains were examined for $\alpha$-haemolysin production and cytotoxicity in addition to haemolysin and necrotoxin production and serotype.

Sources of strains. Faeces were obtained from normal persons, outside hospital, who had not been hospital in-patients and had received no antibiotics during the previous year.

Specimens were obtained from patients with ulcerative colitis, both in relapse and in remission, by swabbing the colonic mucosa at the time of sigmoidoscopy in the out-patient clinic (Cooke et al., 1974).

The introital and urinary strains were from women attending a nephro-urological clinic with symptoms of frequency and dysuria. These patients were followed for at least 3 months after their first attendance. The introital strains were obtained by swabbing round the external urethral meatus with a broth-moistened swab (O'Grady et al., 1970).

Haemolysin production. Solid and liquid media were used as previously (Cooke, 1968). The solid medium used was erythrocyte agar made with horse RBC washed three times. The liquid medium was peptone water containing washed horse RBC. This was inoculated with the strain under test and incubated for $48 \mathrm{~h}$. The presence of a soluble $(\alpha)$ haemolysin was demonstrated in the supernatant of a $2 \frac{1}{2}-\mathrm{h}$ culture in alkaline extract broth as described by Smith (1963).

Necrotoxin production. This was demonstrated by the effect of the intradermal injection of a 6-h broth culture into the skin of a rabbit (Cooke, 1968). The skin was examined 5 days after the injection, when a positive result was indicated by an ulcerated area up to $2.5 \mathrm{~cm}$ in diameter surrounded by an area of inflammation.

Serotyping. Strains were identified as $E$. coli and serotyped with antisera to $O$ types 1-25, 39 and 75, as described previously (Cooke, Ewins and Shooter, 1969).

Cytotoxin production. Haemolytic supernates of broth cultures of $E$. coli were prepared by the method of Smith (1963). Monolayers of chick-embryo fibroblasts were prepared and the culture fluid was replaced by the haemolytic supernate (Chaturvedi et al., 1969). Each test was done in duplicate and control positive and negative tubes were included. The fibroblasts were incubated at $37^{\circ} \mathrm{C}$ and examined after 2 and $4 \mathrm{~h}$ for evidence of destroyed or damaged cells. In a small number of experiments human foetal-colon fibroblasts were used.

\section{TABLE I}

Properties of strains of Escherichia coli isolated from introital swabs, urinary-tract infections, and faeces of normal persons

\begin{tabular}{|c|c|c|c|c|}
\hline \multirow[b]{2}{*}{ Property } & \multicolumn{4}{|c|}{ Percentage frequency of various properties among strains } \\
\hline & $\begin{array}{l}\text { from faeces of } \\
\text { normal persons } \\
\qquad(397)^{*}\end{array}$ & $\begin{array}{l}\text { from introital swabs } \\
\text { that did not give rise } \\
\text { to urinary-tract } \\
\text { infections }(15)^{*}\end{array}$ & $\begin{array}{l}\text { from introital swabs } \\
\text { that did give rise } \\
\text { to urinary-tract } \\
\text { infections }(15)^{*}\end{array}$ & $\begin{array}{l}\text { from urinary- } \\
\text { tract infections } \\
(50)^{*}\end{array}$ \\
\hline $\begin{array}{l}\text { Haemolysin production } \\
\text { in liquid medium } \\
\text { in solid medium } \\
\text { in either medium } \\
\text { Necrotoxin production }\end{array}$ & $\begin{array}{c}14 \dagger \\
5 \S \\
17 \\
99\end{array}$ & $\begin{array}{l}7 \ddagger \\
25 \\
25 \\
7 \|\end{array}$ & $\begin{array}{l}47 \ddagger \\
47 \\
53 \\
60 \|\end{array}$ & $\begin{array}{l}44 \dagger \\
52 \S \\
56 \\
54 \uparrow\end{array}$ \\
\hline $\begin{array}{l}\text { Serotype } \\
\text { O2; O4; O6; O } 75 \\
\text { O non-typable } \\
\text { rough }\end{array}$ & $\begin{array}{l}13 \cdot 6 \\
41 \cdot 1 \\
14 \cdot 1\end{array}$ & $\begin{array}{r}20 \\
40 \\
7\end{array}$ & $\begin{array}{r}47 \\
20 \\
7\end{array}$ & $\begin{array}{l}24 \\
36 \\
16\end{array}$ \\
\hline
\end{tabular}

* Number of strains examined.

$\dagger \mathrm{P}=<0.001 ; \ddagger \mathrm{P}=0.0352 ; \S \mathrm{P}=<0.001 ; \| \mathrm{P}=0.0052 ;$ ๆ $\mathrm{P}=<0.001$. 


\section{RESULTS}

Haemolysin production, necrotoxin production and serotype in strains of $E$. coli isolated from the faeces of normal persons, from urinary-tract infections and from introital swabs are shown in table $I$.

Strains from urinary-tract infections more commonly produced a haemolysin and a necrotoxin and belonged to serotypes $\mathrm{O} 2, \mathrm{O} 4, \mathrm{O} 6$ and $\mathrm{O} 75$ than did strains from normal faeces. Similar differences were found between strains of $E$. coli that had been isolated from introital swabs and subsequently gave rise to infections of the urinary tract, and strains that colonised the external urethral meatus but did not give rise to infection. The significance levels of some of these differences are also given in table I. As a group, the introital strains that gave rise to urinary-tract infections resembled urinary strains in their properties, and the introital strains that did not give rise to infection resembled faecal strains.

The properties of the selected strains used to compare the association between properties in strains of $E$. coli are shown in table II. The production of a haemolysin detectable only on solid medium, was not associated with the presence of $\alpha$-haemolysin; of nine strains studied that produced a haemolysin detectable only on solid medium only one produced an $\alpha$-haemolysin. In contrast, the production of a "liquid" haemolysin was closely associated with

TABLE II

Association of properties in individual strains of Escherichia coli

\begin{tabular}{|c|c|c|c|c|c|}
\hline \multicolumn{5}{|c|}{ Production of } & \multirow{2}{*}{$\begin{array}{l}\text { Number of strains } \\
\text { with the } \\
\text { indicated properties }\end{array}$} \\
\hline $\begin{array}{l}\text { " solid" } \\
\text { haemolysin }\end{array}$ & $\begin{array}{l}\text { "liquid" } \\
\text { haemolysin }\end{array}$ & $\stackrel{\alpha-}{\alpha-}$ & necrotoxin & cytotoxin & \\
\hline - & - & N.T. & - & N.T. & 65 \\
\hline+ & + & + & + & + & 30 \\
\hline+ & + & + & - & + & 20 \\
\hline- & - & N.T. & - & - & 13 \\
\hline- & + & + & - & + & 9 \\
\hline+ & - & - & - & - & 7 \\
\hline- & + & - & - & - & 6 \\
\hline- & - & N.T. & + & N.T. & 6 \\
\hline- & + & + & + & + & 5 \\
\hline - & + & + & - & - & 5 \\
\hline - & - & - & - & - & 4 \\
\hline- & - & - & + & - & 4 \\
\hline+ & + & - & - & - & 2 \\
\hline+ & + & + & + & - & 2 \\
\hline- & - & N.T. & + & - & 2 \\
\hline+ & - & + & - & + & 1 \\
\hline- & + & - & + & - & 1 \\
\hline N.T. & - & N.T. & + & N.T. & 1 \\
\hline- & - & + & - & - & 1 \\
\hline+ & + & + & - & - & 1 \\
\hline+ & - & - & + & - & 1 \\
\hline
\end{tabular}

N.T. $=$ not tested $++=$ positive; $-=$ negative. 
the production of an $\alpha$-haemolysin. Of 81 strains that produced a "liquid " haemolysin, an $\alpha$-haemolysin was detected in 72 .

The production of an $\alpha$-haemolysin was often associated with cytotoxicity in tissue culture. Of $74 \alpha$-haemolytic strains, 66 were cytotoxic in tissue culture, but none of the 20 non-haemolytic organisms examined was cytotoxic. The 24 tests carried out on human foetal-colon fibroblasts gave the same results as with the chick-embryo fibroblasts.

The association observed by other workers between haemolysin and necrotoxin production was present. Of 64 strains that produced a "solid" haemolysin, 31 produced a necrotoxin, but of 121 strains that did not produce a " solid" haemolysin only 19 produced a necrotoxin. Similarly, of 52 strains that produced a "liquid" haemolysin, 38 produced a necrotoxin, while of 134 strains that did not produce a "liquid" haemolysin only 43 produced a necrotoxin.

The association between the production of " solid " and " liquid " haemolysin is of interest. Among strains isolated from urinary-tract infections, all that produced a "liquid" haemolysin also produced a " solid" haemolysin, but of the 10 strains from normal persons that produced a "liquid" haemolysin, six did not produce a "solid" haemolysin.

\section{Discussion}

Two possible sources have been considered for strains of $E$. coli that invade the urinary tract. One suggestion is that these strains are merely those most common in the faeces and that they have no special pathogenicity, a view supported by work showing a similar frequency of different serotypes of $E$. coli in the faeces and in urinary-tract infections (Grüneberg, Leigh and Brumfitt, 1968). The other possibility is that strains that cause urinary-tract infection differ from faecal strains either in their ability to invade or to cause disease. The evidence for special pathogenicity in $E$. coli is based on the amount of $\mathrm{K}$ antigen produced (Glynn et al., 1971) and on the production of haemolysins (Vahlne, 1945).

The results reported here confirm the high incidence of haemolytic $E$. coli among strains causing urinary-tract infections. The number of introital $E$. coli examined was low, because many of the women from whom swabs were taken either could not be followed up or were treated with antibiotics, but the results indicate that strains that colonise the introitus and give rise to infections resemble strains isolated from urine, whereas strains that do not give rise to infections resemble faecal strains. The outcome of introital colonisation may in part therefore depend on the nature of the colonising organism.

The work on the association of properties within strains of $E$. coli showed the expected correlation between haemolysin and necrotoxin production. $\alpha$-Haemolysin production is associated with the production of a "liquid" haemolysin and with cytotoxicity. Chaturvedi et al. (1969) demonstrated the close association between haemolysin production and cytotoxicity in one strain of $E$. coli (serotype 06 , the standard haemolytic strain). We have 
confirmed that this association is widespread and that strains with these properties frequently cause urinary-tract infections. The absence in urinarytract infections of strains that produce a "liquid" but not a "solid" haemolysin indicates the importance of the production of non-diffusible haemolysins.

\section{SUMMARY}

Strains of Escherichia coli causing urinary-tract infections were found to be more commonly haemolytic than were faecal strains. Strains from the introitus that subsequently gave rise to urinary-tract infections resembled urinary strains and those that did not give rise to infections resembled faecal strains.

$\alpha$-Haemolysin production was closely associated, in strains from a variety of different sources, with the production of a haemolysin detectable in liquid medium and with cytotoxicity in tissue culture.

We are indebted to Professor F. W. O'Grady, who made available the introital and urinary strains of $E$. coli, and to Miss G. V. Martin for assistance with the tissue-culture work.

This investigation was supported by a grant from the St Mark's Foundation.

\section{REFERENCES}

Chaturvedi, U. C., Mathur, A., Khan, A. M. and Mehrotra, R. M. L. 1969. Cytotoxicity of filtrates of haemolytic E. coli. J. med. Microbiol., 2, 211.

Cooke, E. M. 1968. Properties of strains of Escherichia coli isolated from the faeces of patients with ulcerative colitis, patients with acute diarrhoea and normal persons. J. Path. Bact., 95, 101.

Cooke, E. M., Ewins, S. P., Hywel-Jones, J. ANd Lennard-Jones, J. E. 1974. Properties of strains of Escherichia coli carried in different phases of ulcerative colitis. Gut, 15, 143.

Cooke, E. M., Ewins, S. P. ANd Shooter, R. A. 1969. Changing faecal population of Escherichia coli in hospital medical patients. Brit. med. J., 4, 593.

Dudgeon, L. S., Wordley, E. ANd BaWtree, F. 1921. On Bacillus coli infections of the urinary tract especially in relation to haemolytic organisms. J. Hyg., Camb., 20, 137.

GlynN, A. A., BRUMfitT, W. AND Howard, C. J. 1971. " K" antigens of Escherichia coli and renal involvement in urinary tract infections. Lancet, 1, 514.

Grüneberg, R. N., Leigh, D. A. AND BrumfitT, W. 1968. Escherichia coli serotypes in urinary tract infection: studies in domiciliary, ante-natal and hospital practice. In Urinary tract infection, edited by F. O'Grady and W. Brumfitt, London, p. 68.

O'Grady, F. W., Richards, B., McSherry, M.A., O'Farrell, S. M. and Cattell, W. R. 1970. Introital enterobacteria, urinary infections and the urethral syndrome. Lancet, 2, 1208.

Ross, C. A. C. (1959). Mucinase activity of intestinal organisms. J. Path. Bact., 77, 642.

SJöstedT, S. 1946. Pathogenicity of certain serological types of E. coli. Acta path. microbiol. scand., Suppl. 63.

Sмith, H. W. 1963. Haemolysins of Escherichia coli. J. Path. Bact., 85, 197.

TAylor, J., Maltby, M. P. ANd Payne, J. M. 1958. Factors influencing the response of ligated rabbit gut segments to injected Escherichia coli. J. Path. Bact., 76, 491.

VAHLNE, G. 1945. Serological typing of the colon bacteria. Acta path. microbiol. scand., Suppl. 62. 